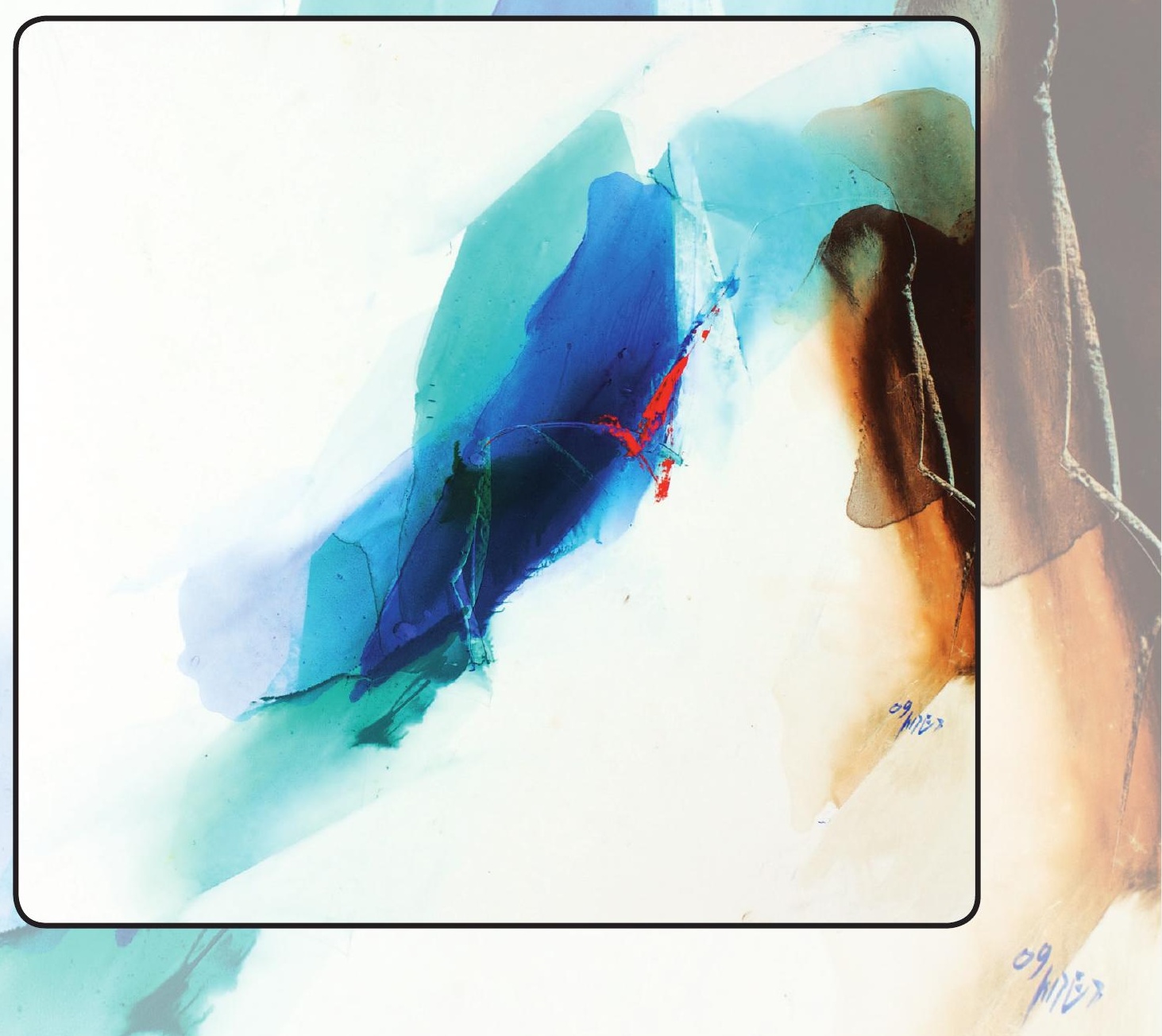




\section{Hommage Aux 12 apotres}

Óleo sobre lienzo

$120 \times 120 \mathrm{cms}$

2009

Colección Privada

Universidad Santo Tomás 


\title{
LA CLÁUSULA COMPROMISORIA Y LA CLÁUSULA PENAL EN EL CONTRATO PRIVADO: DETERMINACIÓN DEL JUEZ COMPETENTE Y DEL PROCEDIMIENTO APLICABLE PARA LA SOLUCIÓN DE CONTROVERSIAS
}

\section{Juan Carlos Quiñones Guzmán}

Universidad Santo Tomás, Seccional Bucaramanga (Col); Especialista en Derecho Administrativo (Col), Pontificia Universidad Javeriana; Especialista en Derecho Comercial, Pontificia Universidad Javeriana (Col). E-mail: juancarlosqg7@hotmail.com

\begin{abstract}
Resumen
El presente texto tiene como propósito hacer una corta revisión, a la luz de los pronunciamientos de la Corte Constitucional, sobre las competencias del juez en aquellos casos en los cuales una de la partes pretende hacer valer ejecutivamente una cláusula penal y la otra, ante tal situación, propone la excepción de cláusula compromisoria.
\end{abstract}

\section{Palabras clave}

Cláusula penal, cláusula compromisoria, juez.

\begin{abstract}
This text is intended to make a short review, in light of the rulings of the Constitutional Court on the powers of the judge in those cases in which one of the parties intends to assert executive-a penalty clause and the other, before such situation, proposes the exception clause.
\end{abstract}

\section{Key Words}

Penalty clause, arbitration clause, Judge. 



\section{LA CLÁUSULA COMPROMISORIA Y LA CLÁUSULA PENAL EN EL CONTRATO PRIVADO: DETERMINACIÓN DEL JUEZ COMPETENTE Y DEL PROCEDIMIENTO APLICABLE PARA LA SOLUCIÓN DE CONTROVERSIAS*}

Juan Carlos Quiñones Guzmán

En frecuentes ocasiones los criterios de los jueces para resolver controversias jurídicas que se fundamentan en unos mismos supuestos de hecho son disímiles, circunstancia que, en precisos escenarios, puede vulnerar derechos fundamentales y configurarse en una vía de hecho ${ }^{1}$. Uno de estos escenarios es el proceso ejecutivo en el cual la parte demandante, con base en una cláusula penal pactada en un contrato pretende ejecutar al demandado, quien, al hacer uso igualmente de lo acordado en el contrato, propone la excepción previa "cláusula compromisoria", con fundamento

* El presente texto tiene como propósito hacer una corta revisión, a la luz de los pronunciamientos de la Corte Constitucional, sobre las competencias del juez en aquellos casos en los cuales una de la partes pretende hacer valer ejecutivamente una cláusula penal y la otra, ante tal situación, propone la excepción de cláusula compromisoria.

1 La Corte Constitucional en la sentencia T-189 de 2005 explicó el concepto "vía de hecho" en los siguientes términos: "La evolución de la jurisprudencia condujo a que, desde la Sentencia T-231 de 1994 (M.P. Eduardo Cifuentes Muñoz) se determinara cuáles defectos podían conducir a que una sentencia fuera calificada como una vía de hecho. En la providencia se indicaron los casos excepcionales en que procede la acción de tutela, indicando que se configura una vía de hecho cuando se presenta, al menos, uno de los siguientes vicios o defectos protuberantes: (1) defecto sustantivo, que se produce cuando la decisión controvertida se funda en una norma indiscutiblemente inaplicable; (2) defecto fáctico, que ocurre cuando resulta indudable que el juez carece de sustento probatorio suficiente para proceder a aplicar el supuesto legal en el que sustenta la decisión; (3) defecto orgánico, se presenta cuando el funcionario judicial que profirió la providencia impugnada, carece, absolutamente, de competencia para ello; y, (4) defecto procedimental que aparece en aquellos eventos en los que se actuó completamente al margen del procedimiento establecido". 
en la estipulación contractual que contiene el pacto arbitral. En este sentido, el presente artículo tiene como propósito determinar, a la luz de los pronunciamientos de la Corte Constitucional, el juez competente en aquellos casos en los cuales una de la partes pretende hacer valer ejecutivamente una cláusula penal y la otra, ante tal situación, propone la excepción de cláusula compromisoria.

En los contratos privados es usual redactar cláusulas penales en las que se indica que las sanciones allí previstas para el contratante incumplido prestan mérito ejecutivo sin necesidad de declaración judicial. A su turno, en las cláusulas compromisorias es común que se acuerde que las controversias que surjan entre las partes con ocasión de la celebración, ejecución y liquidación del contrato serán resueltas por un Tribunal de Arbitramento. De esta forma, en el evento en que se presenten diferencias entre las partes durante el desarrollo del contrato, relacionadas con incumplimientos advertidos como causa para la configuración de la pena, o como controversias objeto del arbitraje, cualquiera de éstas puede demandar ejecutivamente la efectividad de la cláusula penal o convocar al tribunal de arbitramento para que resuelva los desacuerdos. Ante esta realidad, la autoridad judicial deberá tener en cuenta los precedentes jurisprudenciales de la Corte Constitucional, a fin de identificar el juez competente para conocer de la causa, y de esta forma evitar la configuración de una vía de hecho con su decisión. Con el fin de hacer un aporte a este propósito, a continuación se hará un análisis de la naturaleza, alcances y efectos de la cláusula compromisoria y de la cláusula penal en el derecho privado colombiano, así como de sus incidencias procesales desde la interpretación de la Corte Constitucional.

\section{El arbitraje es un contrato mediante el cual las partes delegan a un tercero la solución de controversias, renunciando a acudir a la jurisdicción estatal}

El artículo 116 de la Constitución Política, en el cuarto inciso, establece:

"Los particulares pueden ser investidos transitoriamente de la función de administrar justicia en la condición de jurados en las causas criminales, conciliadores o en la de árbitros habilitados por las partes para proferir fallos en derecho o en equidad, en los términos que determine la ley".

Por su parte, la Ley 446 de $1998^{2}$, en su artículo 111, define el arbitraje en los siguientes términos:

“(...) mecanismo por medio del cual las partes involucradas en un conflicto de carácter transigible, defieren su solución a un tribunal arbitral, el cual queda

2 Por la cual se adoptan como legislación permanente algunas normas del Decreto 2651 de 1991, se modifican algunas del Código de Procedimiento Civil, se derogan otras de la Ley 23 de 1991 y del Decreto 2279 de 1989, se modifican y expiden normas del Código Contencioso Administrativo y se dictan otras disposiciones sobre descongestión, eficiencia y acceso a la justicia. 
transitoriamente investido de la facultad de administrar justicia, profiriendo una decisión denominada laudo arbitral”.

Más adelante, la Ley 446 de 1998 en su artículo 115, establece que por medio del pacto arbitral -que comprende la cláusula compromisoria y el compromiso- las partes se obligan a someter sus diferencias a la decisión de un Tribunal Arbitral, renunciando a hacer valer sus pretensiones ante los jueces. Y, finalmente, el artículo 116 de la mentada ley señala que se entenderá por cláusula compromisoria, el pacto contenido en un contrato o en documento anexo a él, en virtud del cual los contratantes acuerdan someter las eventuales diferencias que puedan seguir con ocasión del mismo, a la decisión de un Tribunal Arbitral.

Es evidente, entonces, que de conformidad con la autorización constitucional, las partes de un contrato pueden habilitar a particulares para que, transitoriamente, administren justicia mediante el pacto arbitral, y que, para el caso de la cláusula compromisoria, dicha autorización está comprendida en un acuerdo mediante el cual las partes convienen someter las diferencias que surjan con ocasión del contrato a un tribunal arbitral y renuncien a hacer valer su pretensiones ante los jueces estatales. De conformidad con lo anterior, la cláusula compromisoria es en sí misma un contrato. En este sentido se ha pronunciado la jurisprudencia constitucional y la doctrina autorizada. En efecto, la Corte Constitucional en Sentencia de Unificación del 14 de marzo de 2007, señaló:

“(...) Por mandato expreso del constituyente, la voluntad autónoma de las partes en conflicto es el pilar central sobre el que se estructura el sistema de arbitramento en nuestro ordenamiento jurídico. El artículo 116 de la Constitución Política define el arbitramento con base en el acuerdo de las partes, que proporciona su punto de partida y la habilitación para que los árbitros puedan impartir justicia en relación con un conflicto concreto. En tal medida, la autoridad de los árbitros se funda en la existencia de un acuerdo de voluntades previo y libre entre las partes enfrentadas, en el sentido de sustraer la resolución de sus disputas del sistema estatal de administración de justicia y atribuirla a particulares (...)”3.

A su turno, el profesor Eduardo Silva Romero ${ }^{4}$ ha precisado en torno a la naturaleza contractual del pacto arbitral lo siguiente:

“(...) El arbitraje proviene de un contrato celebrado entre las partes de un litigio por medio del cual éstas deciden que toda controversia actual o que pueda surgir de un contrato o con relación al mismo debe ser sometida al conocimiento de un tercero llamado tribunal arbitral". ${ }^{5}$

3 Corte Constitucional, Sentencia SU-174 del 2007, M.P. Manuel José Cepeda.

4 Abogado y Colegial del Colegio Mayor de Nuestra Señora del Rosario (Bogotá); profesor titular y director de la Línea de investigación sobre arbitraje de la misma Universidad; doctor en derecho de la Universidad Panthéon - Assas (París II); ex secretario general adjunto de la Corte Internacional de Arbitraje de la Cámara de Comercio Internacional.

5 El Contrato de Arbitraje, Editorial Legis, Primera Edición, 2005, pág. XVIII. 
El inciso $3^{\circ}$ del artículo 116 de la Ley 446 de 1998 establece que si las partes no señalan en la cláusula compromisoria las reglas de procedimiento aplicables en la solución de su conflicto, se entenderá que el arbitraje es legal. Por su parte, los capítulos $2^{\circ}$ y $3^{\circ}$ del Título II de la Ley 446 de 1998 regulan el procedimiento legal del arbitraje.

\section{La cláusula penal y su virtualidad para prestar mérito ejecutivo}

La cláusula penal está regulada por el artículo 1592 y subsiguientes del Código Civil en los siguientes términos:

La cláusula penal es aquella en que una persona, para asegurar el cumplimiento de una obligación, se sujeta a una pena que consiste en dar o hacer algo en caso de no ejecutar o retardar la obligación principal.

La jurisprudencia de la Corte Suprema de Justicia ha precisado que la cláusula penal cumple tres funciones ${ }^{6}$ : (i). Servir de apremio al deudor; (ii). Servir de garantía o caución, y (iii). Estimar anticipadamente los perjuicios.

La función de apremio de la cláusula penal encuentra su fundamento en la última parte del artículo 1594 del Código Civil, cuando establece:

Antes de constituirse el deudor en mora, no puede el acreedor demandar a su arbitrio la obligación principal o la pena, sino sólo la obligación principal; ni constituido el deudor en mora, puede el acreedor pedir a un tiempo el cumplimiento de la obligación principal y la pena, sino cualquiera de las dos cosas a su arbitrio; a menos que aparezca haberse estipulado la pena por el simple retardo, o a menos que se haya estipulado que por el pago de la pena no entienda extinguida la obligación principal" (Negrillas por fuera del texto original).

Según lo determina la anterior norma, el simple retardo del deudor en el cumplimiento de la obligación principal puede estipularse como un supuesto de causación de la cláusula penal como apremio, circunstancia que no lo exonera de cumplir con la prestación principal a su cargo.

La cláusula penal como garantía o caución, según lo ha precisado la doctrina, "opera cuando un tercero, distinto del deudor principal, se obliga a pagar la pena en caso que éste no cumpla su obligación"7.

La estimación anticipada de perjuicios es probablemente la más usual de las funciones de la cláusula penal y consiste en que las partes de un contrato estiman convencionalmente y de manera anticipada los perjuicios que se deriven de un probable incumplimiento de las prestaciones a su cargo. Según lo ha señalado la

$6 \quad$ Corte Suprema de Justicia, Sala de Casación Civil, Sentencia del 7 de octubre de 1976.

7 SUESCÚN MELO, Jorge, Derecho Privado Estudios de Derecho Civil y Comercial Contemporáneo, Editorial Legis, Segunda Edición, 2003, pág. 44. 
Corte Suprema de Justicia ${ }^{8}$, las bondades de estipular la cláusula penal como estimación anticipada de perjuicios son: (i). El acreedor se libera de probar los perjuicios derivados del incumplimiento; (ii). El incumplimiento de la obligación principal hace presumir la culpa del deudor, y (iii). Evita la controversia sobre la cuantía de los perjuicios sufridos por el acreedor.

En relación con el mérito ejecutivo de la cláusula penal, no debe perderse de vista que el fundamento para su exigibilidad es que haya mediado un incumplimiento; es éste criterio el denominador común de las diferentes funciones que cumple la cláusula penal y que fueron anteriormente explicadas. En este sentido, no existe mérito ejecutivo de la referida cláusula cuando no hay certeza de la existencia del incumplimiento, motivo por el cual el proceso ejecutivo para intentar el cobro coercitivo de la pena es improcedente, en tanto que no se ha configurado una obligación clara, expresa y exigible a cargo del demandado y a favor del demandante.

\section{Determinación del juez competente y del proceso judicial procedente para solucionar las controversias}

En el evento que, frente al surgimiento de controversias contractuales entre las partes, exista una colisión entre lo previsto en la cláusula penal y en la cláusula compromisoria del contrato, que afecte la determinación del proceso judicial procedente y del juez competente para resolverlas, deberá analizarse en primera instancia si la cláusula compromisoria excluye de su ámbito de aplicación los supuestos de hecho estipulados en la cláusula penal. En efecto, el intérprete del contrato debe identificar si en la cláusula compromisoria las partes manifestaron su voluntad explícita de que los eventos de incumplimiento previstos en la cláusula penal hacen parte o no del objeto de arbitramento.

Sobre este particular, debe resaltarse que la única autoridad judicial competente para interpretar los alcances de la cláusula compromisoria es el Tribunal de Arbitramento. En este sentido se pronunció recientemente la Corte Constitucional, mediante la sentencia T - 1224 de $2008^{9}$, con ocasión de una decisión de la Sala Civil-Familia del Tribunal Superior del Distrito Judicial de Bucaramanga ${ }^{10}$ proferida en un proceso ejecutivo ${ }^{11}$ en el que la parte demandada propuso la excepción previa de cláusula compromisoria, frente a la demanda ejecutiva promovida con base en una

$8 \quad$ Corte Suprema de Justicia, Sala de Casación Civil, Sentencia del 7 de octubre de 1976.

9 Sentencia proferida el 5 de diciembre de 2008 por la Sala Segunda de Revisión, M.P. Manuel José Cepeda.

10 Auto de fecha 15 de febrero de 2007 M.P. Dr. José Mauricio Marín Mora. Expediente No. 2006-191 del Juzgado Primero Civil del Circuito de Bucaramanga.

11 Proceso ejecutivo iniciado por Central Termoeléctrica El Morro 1 S.A. E.S.P. contra la Electrificadora de Santander S.A. E.S.P. en el juzgado Primero Civil del Circuito de Bucaramanga, con el número de radicación 2006-191 
cláusula penal. En esta oportunidad, la Sala Civil-Familia revocó el auto proferido por el juez de primera instancia en el que el a-quo declaró probada la excepción previa cláusula compromisoria, disponiendo en consecuencia la terminación del proceso. En su lugar, el Tribunal ordenó la continuación del proceso ejecutivo, argumentando que

“(...) el cobro, directo o judicial, de la cláusula penal, en los eventos que la configuran, no quedó sometido a la cláusula compromisoria en ninguna de las modalidades allí indicadas, incluyendo el arbitramento, por cuanto sabido es que el Tribunal que para el efecto se convoque e integre emite en últimas una declaración judicial, presupuesto este que precisamente se excluyó respecto del ejercicio del derecho a cobrar la cláusula penal, como con precedencia se destacó" ${ }^{2}$.

Al respecto, la Corte Constitucional recordó que sólo el tribunal de arbitramento es el legitimado para determinar su competencia en virtud de la regla kompetenzkompetenz, según la cual los árbitros son titulares de la competencia para decidir sobre su propia competencia; esto con anterioridad a cualquier instancia judicial que haya sido activada por las partes, los que no obsta para que esta decisión sea recurrida por las partes, por ejemplo a través del recurso de anulación, y de esta manera se pronuncie el juez estatal sobre la competencia del tribunal de arbitramento" $" 13$

En este sentido, el juez ordinario no puede, so pretexto de interpretar el contrato, determinar si una controversia está o no contenida en el ámbito de la cláusula compromisoria, en tanto que la única autoridad judicial competente para hacerlo es el propio tribunal de arbitramento.

La regla kompetenz-kompetenz en la jurisprudencia constitucional.

La regla kompetenz - kompetenz fue explicada por la Corte Constitucional en la sentencia SU 147 de 2007, en los siguientes términos:

"El principio kompetenz-kompetenz, según el cual los árbitros tienen competencia para decidir sobre su propia competencia está expresamente plasmado en la legislación colombiana (artículo 147, numeral 2 del Decreto 1818 de 1998) y goza de reconocimiento prácticamente uniforme a nivel del derecho comparado ${ }^{14}$, las convenciones internacionales que regulan temas de arbitramento ${ }^{15}$, las reglas de

12 Sentencia T-1224 de 2008, pág. 3.

13 Ibídem, pág. 10.

14 Art. 1466, Código de Procedimiento Civil de Francia; Art. 186.1, Ley de Derecho Internacional Privado de Suiza, 1987; Art. 8-1 del Concordato Suizo; Art. 1697 del Código Judicial de Bélgica, 1972; Art. 1052(1) del Código de Procedimiento Civil de Países Bajos, 1986; Art. 23(3) de la Ley 36 de 1988 de España; Art. 21(1) de la Ley 31/86 de Portugal, sobre arbitraje voluntario; Sección 30 de la Ley de Arbitraje de Inglaterra, 1996; Art. 1040 del ZPO Alemán, 1997

15 Ver el art. V-3 del Convenio Europeo sobre Arbitraje Comercial Internacional; el art. 41 de la Convención de Washington que creó el CIADI; y la Ley Modelo de UNCITRAL, Art. 16-3 
los principales centros de arbitraje internacional ${ }^{16}$, las reglas uniformes establecidas en el ámbito internacional para el desarrollo de procesos arbitrales ${ }^{17}$ y la doctrina especializada en la materia ${ }^{18}$, así como decisiones judiciales adoptadas por tribunales internacionales ${ }^{19}$. En virtud de este principio, los árbitros tienen la potestad, legalmente conferida, de determinar si tiene competencia para conocer de una determinada pretensión relativa a una disputa entre las partes, en virtud del pacto arbitral que le ha dado fundamento.

(...) Esta competencia básica no implica, por supuesto, que los árbitros sean los únicos jueces con potestad para establecer el alcance de su propia competencia. Las decisiones del tribunal arbitral sobre su propia competencia también pueden ser objeto de recursos judiciales como el de anulación, con base en la causal contenida en el numeral 8 del artículo 38 del Decreto 2279 de 1989 (el cual fue compilado en el numeral 8 del artículo 163 del Decreto 1818 de 1998) y en el numeral 4 del artículo 72 de la Ley 80 de 1993 (el cual fue compilado en el numeral 4 del artículo 230 del Decreto 1818 de 1998). Sin embargo, el principio kompetenzkompetenz les confiere a los árbitros un margen interpretativo autónomo para definir el alcance de su propia competencia, y se deriva de la proposición según la cual no ha de descartarse prima facie que las partes habilitantes han confiado en la capacidad de los árbitros de adoptar decisiones definitivas en relación con los conflictos que se someten a su conocimiento; el principio kompetenz-kompetenz permite, así, que los árbitros sean los primeros jueces de su propia competencia, con anterioridad a cualquier instancia judicial activada por las partes".

Con base en la anterior sentencia de unificación de la Corte Constitucional, se encuentra que la regla kompetenz-kompetenz implica una facultad exclusiva y excluyente del tribunal de arbitramento para determinar autónomamente su competencia judicial a fin de conocer los conflictos que se sometan a su consideración, con base en el pacto arbitral que las partes hayan ajustado.

Lo anterior significa que el juez estatal no puede, so pretexto de interpretar los alcances del pacto arbitral, usurpar las competencias exclusivas del tribunal de arbitramento, ya que solamente los árbitros que integran el tribunal están habilitados constitucional y legalmente para decidir sobre su propia competencia.

Al respecto, el artículo 124 de la Ley 446 de 1998, relativo a la primera audiencia de trámite en el procedimiento arbitral, establece:

16 Art. 15.1 de las Reglas de la American Arbitration Association; Art. 8.3. de las Reglas de la Cámara de Comercio Internacional; Art. 14.1 de la Corte de Arbitraje Internacional de Londres (LCIA).

17 Art. 21.1 de las Reglas de UNCITRAL

18 Ver a este respecto: Emmanuel Gaillard y John Savage (eds.): Fouchard Gaillard Goldman "On International Commercial Arbitration”. Kluwer Law International, 1999. También se puede consultar: Bühring-Uhle, Christian: "Arbitration and Mediation in International Business". Kluwer Law International, 1996, p. 42-44; Caivano, Roque: "Arbitraje", Villela Editor, Buenos Aires, 2000; Várady, Tibor, Barceló, John y von Mehren, Arthur: "International Comercial Arbitration". American Casebook Series - West Group, St. Paul, 1999, p. 111.

19 Ver el caso Nottebohm (1953) y el caso relativo al Laudo Arbitral adoptado por el Rey de España el 23 de diciembre de 1906 (1960), ambos de la Corte Internacional de Justicia. 
"La primera audiencia de trámite se desarrollará así:

1. Se leerá el documento que contenga el compromiso o la cláusula compromisoria y las cuestiones sometidas a decisión arbitral y se expresarán las pretensiones de las partes estimando razonablemente su cuantía.

2. El tribunal resolverá sobre su propia competencia mediante auto que sólo es susceptible de recurso de reposición.

3. El tribunal resolverá sobre las pruebas pedidas por las partes y las que de oficio estime necesarias.

4. Si del asunto estuviere conociendo la justicia ordinaria recibirá la actuación en el estado que se encuentre en materia probatoria y practicará las pruebas que falten, salvo acuerdo de las partes en contrario.

Fijará fecha y hora para la siguiente audiencia.

PARÁGRAFO. Si el Tribunal decide que no es competente, se extinguirán definitivamente los efectos del pacto arbitral.”. (Las negrillas y subrayas son mías)".

Por su parte, el artículo 163 del Decreto 1818 de 1998, "Por medio del cual se expide el Estatuto de los mecanismos alternativos de solución de conflictos", prescribe:

"Artículo 163. Son causales de anulación del laudo las siguientes:

2. No haberse constituido el Tribunal de Arbitramento en forma legal, siempre que esta causal haya sido alegada de modo expreso en la primera audiencia de trámite.

(..)

8. Haberse recaído el laudo sobre puntos no sujetos a la decisión de los árbitros o haberse concedido más de lo pedido y

9. No haberse decidido sobre cuestiones sujetas al arbitramento.”.

Como se aprecia, la regulación normativa del arbitramento en Colombia establece con toda claridad que el tribunal de arbitramento es quien decide acerca de su propia competencia en la primera audiencia del trámite arbitral y que la jurisdicción estatal sólo se puede pronunciarse acerca de la competencia del tribunal con ocasión de la decisión del recurso de anulación.

Por lo anteriormente expuesto, si en un proceso ejecutivo en el que se cobra una cláusula penal contenida en un contrato en el que igualmente fue ajustada por las partes una cláusula compromisoria, el demandado propone la excepción previa 
cláusula compromisoria y declara su voluntad de acogerse a la misma, el juez debe declarar probada la excepción - previa verificación de la existencia de la cláusula compromisoria- y disponer la terminación inmediata del proceso. A esta conclusión se arriba, por las siguientes razones:

(i). Al ser la cláusula compromisoria un contrato, si la parte demandada en un proceso ejecutivo iniciado con base en una cláusula penal, manifiesta su voluntad de acogerse a lo estipulado con su cocontratante en el pacto arbitral, el juez estatal debe respetar el acuerdo, bajo el entendido que el tribunal de arbitramento es el único juez del contrato;

(ii). El juez estatal no es competente para determinar si una controversia hace parte o no de la cláusula compromisoria, en tanto que sólo el tribunal de arbitramento es el competente en virtud de la regla kompetenz - kompetenz, y

(iii). De conformidad con la jurisprudencia constitucional, el juez estatal no puede usurpar la competencia exclusiva del tribunal de arbitramento, so pena de incurrir en una vía de hecho.

\section{REFERENCIAS}

Bühring-Uhle, Christian. (1996). Arbitration and Mediation in International Business. Kluwer Law International.

Caivano, Roque. (2000). Arbitraje, Villela Editor, Buenos Aires.

Código de Procedimiento Civil. Ed. Legis.

Convenio Europeo sobre Arbitraje Comercial Internacional, Convención de Washington - CIADI. -

Corte Constitucional:

Sentencia T-189 de 2005, M.P. Manuel José Cepeda Espinosa.

Sentencia T-231 de 1994, M.P. Eduardo Cifuentes Muñoz.

Sentencia SU-174 del 2007, M.P. Manuel José Cepeda.

Sala de Casación Civil, Sentencia del 7 de octubre de 1976.

Decreto 2651 de 1991, Normas transitorias para descongestionar despachos judiciales.

Decreto 2279 de 1989, Sistema de solución de conflictos entre particulares.

El Contrato de Arbitraje. (2005). Editorial Legis, Primera Edición.

Emmanuel Gaillard y John Savage (eds.). (1999). Fouchard Gaillard Goldman “On International Commercial Arbitration”. Kluwer Law International.

Ley Modelo de UNCITRAL. 
Ley 23 de 1991, Mecanismos para descongestión de despachos judiciales.

Suescún Melo, Jorge. (2003), Derecho Privado Estudios de Derecho Civil y Comercial Contemporáneo, Editorial Legis, Segunda Edición.

Várady, Tibor, Barceló, John; von Mehren, Arthur. (1999). International Comercial Arbitration. American Casebook Series - West Group, St. Paul. 


\section{NORMAS DE PUBLICACIÓN}

La revista IUSTITIA de la Facultad de Derecho Universidad Santo Tomás Bucaramanga, atendiendo al Departamento Administrativo de Ciencia, Tecnología e Innovación, Colciencias y el Sistema Nacional de Indexación y Homologación de Revistas Especializadas de CT+ -Servicio de Indexación, expone las normas de publicación necesarias para la presentación de contribuciones:

Para la aceptación de los artículos por parte del Comité Editorial, se exigirá, que los artículos sean inéditos y originales (sin publicación parcial o total).

El artículo debe estar acompañado del Curriculum Vitae completo del autor: nombre completo del autor, fecha completa de nacimiento, nacionalidad, nivel de escolaridad, nombre de la institución, centro de investigación, o institución a la cual pertenece, cargo que desempeña. Las publicaciones de artículos y reseñas de capítulos de libros y libros deben presentarse (en el curriculum) con toda la información correspondiente: Título, nombre de la revista o compilación, ISSN o ISBN, número de páginas total del texto completo, número de páginas del artículo o capítulo, año de publicación, editorial y país.

El texto debe presentarse en medio magnético, en formato Word, Normas APA, cuartillas 25 - 30, espacio medio, en letra Times New Roman 12, debe tener un resumen no superior a 10 renglones, abstract, palabras clave, key words. En relación con los anexos deben adjuntarse la lista de gráficas y cuadros, con su correspondiente numeración y página. Las tablas y figuras deben presentarse en formato original para poder hacer los ajustes necesarios de edición.

Los artículos recibidos serán remitidos a pares evaluadores, a quienes se les solicitara tener en cuenta en la evaluación, la calidad y el rigor académico del texto, como también la exigencia de las normas correspondientes a los trabajos académicos de publicación.

Recepción de artículos: Revista IUSTITIA: RevistaIUSTITIA@ustabuca.edu.co; coordinvder-ustabuca@hotmail.com

CP- Dirección para correspondencia (Sede Bucaramanga): Cra 18 No. 9-27. Bucaramanga - Santander - Colombia. PBX: 6800801 Ext. 2506.

La convocatoria (2010) para recibir artículos será entre Marzo 1 - Agosto 31. El idioma de publicación es el español, se aceptan artículos en inglés, francés, italiano y portugués. El Comité Editorial enviará comunicación sobre la aprobación o no de artículo, en un término no mayor a cuatro (4) meses.

Actualmente se tramitan procesos de registro ante la comunidad especializada. 
Esta obra se terminó de imprimir en el mes Diciembre de 2009

en la Universidad Santo Tomás Seccional Bucaramanga 